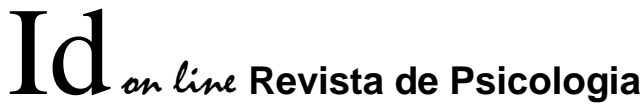

Editada desde Fevereiro de 2007

Ano 6, No.17, Julho de 2012

ISSN 1981-1179

\section{EDITORA RESPONSÁVEL}

Gislene Farias de Oliveira

\section{COLABORADORES}

Ana Marília Barbosa Sampaio; Adelmar de Sousa Marinho Neto; Alisson de Meneses Pontes; Débora dos Santos Silva; Débora Hipólito Lisboa Pontes; Diana Figueiredo Barbosa; Francisca Ergovânia Batista de Brito; Francisco de Assis Soares; Gildevan Estrela Dantas; Jailma dos Santos Barbosa; Maria Rejane Ramalho; Michele da Silva Teixeira; Patrícia Nunes da Fonseca' Raul Max Lucas da Costa; Sandra Maria Santos; Sidney Medeiros de Oliveira; Solania Eugênio Santos Maia; Weilher Feitosa de Melo; Raissa Araújo Rolim.

\section{CONSELHO EDITORIAL}

Anna Christina F. de Carvalho - URCA/CE Cláudia Maria de Moura Pierre - URCA/CE Francinete A. de Oliveira Giffoni - UFC/CE

Gislene Farias de Oliveira - UFC/CE Jadcely Rodrigues Vieira - UECG/PB

Patrícia Nunes Fonseca - UFPB/PB

\section{INTERNET}

http://idonline.net.br

E-mail: revistaidonline2@gmail.com

\section{CAPA E ARTE FINAL}

Athena de Albuquerque Farias athena.farias@gmail.com

\section{REDAÇÃO E ADMINISTRAÇÃO Projeto Persona}

Rua Profa. Sílvia Ferreira, 442/303,

Piedade, Jaboatão dos Guararapes - PE CEP: $54.400-530$

Fone: 081 - 3342-0668

E-mail: projetopersona@yahoo.com.br

\title{
Dados Internacionais de Catalogação
}

Id on line: Revista de Psicologia / Gislene Farias de Oliveira (Org.). 1 ed. v.1. n.17. Jaboatão dos Guararapes, PE: Projeto Persona, Julho, 2012. 144p.

Vários autores

Bibliografia

ISSN 1981-1179

1. Psicologia 2. Saúde 3. Saúde emocional 4. Educação. 5. Psicologia Social. I. Projeto Persona - Jaboatão dos Guararapes - Pernambuco.

\section{Índice para catálogo sistemático: 1. Psicologia 614}

Reservados todos os direitos de publicação à:

PROJETO PERSONA

Endereço: Rua Profa. Sílvia Ferreira, 442/ 303

Piedade, Jaboatão dos Guararapes - PE. CEP: $54.400-530$

Telefone: +55 (81) 3342-0668. E-mail: projetopersona@yahoo.com.br 